the protocol as such and implementing the research locally. They propose that such a split is possible and give details of the solution to the difficulties multi-location researchers face. Their solution, which is the one which the authors designed on behalf of the Department of Health in 1992, involves three tiers of review: national (scientific review) regional and local. These proposals have been supplanted by more recent ones from the Chief Medical Officer; however, there are definite echoes of the original Swansea ideas in what is now to be implemented.

Finally there is a rather nice chapter which looks at some options for future development, including the possibility of research ethics committees being put on a statutory basis; research ethics committees beginning to consider the economic implications of innovation; the development of hospital (practice) ethics committees, and finally the ethical review of health policy.

This is a useful book, and I would happily recommend it to anyone who sits on a research ethics committee, or who is thinking of sitting on one, and also to anyone who conducts research on humans. Donald Evans and Martyn Evans have provided us with a good addition to our libraries, and one which is made all the more enjoyable for the witty quotations throughout the book.

CLAIRE FOSTER

Centre of Medical Law and Ethics, King's College, London

\section{Society's Choices - Social and Ethical Decision Making in Biomedicine}

Edited by R E Bulger, E M Bobby and $H$ V Fineburg, Washington DC, National Academy Press, 1995, $£ 48.95$

It is said that you cannot judge a book by its cover. Certainly this is true for the British reader of Society's Choices. It has the appearance of a weighty and scholarly study of the general principles of social and ethical decisionmaking in biomedicine. In fact it is the report of a committee commissioned to look at the specific problem of what structures should exist in the USA to address bioethical issues, published together with its background papers.
Such a report in the United Kingdom would be published in the sober livery of HMSO or similar bodies. It is the well-recognised ethnocentricity of American thinking, as well as the attractive and lively cover, which conceals this from the casual browser. In most of its five hundred pages it is assumed that this is solely a problem for the USA, and that a solution for that society is the only one for consideration.

The book analyses the role of various interest groups, of forces such as religious belief, and the various commissions and task forces which have addressed both specific issues and had more general remits over bioethical matters. Apart from a brief review of French, Danish and UK approaches, and one more detailed French case study in the background papers, the issues are, however, discussed entirely in the context of American institutions and social forces. An account of the role of the judiciary, the executive and the legislature in formulating health policy, for instance, considers only US examples. The role of these institutions in societies such as the countries of the European Union, where their constitutional relationships are very different, is not examined.

The book is thus of considerable value to anyone who is interested in the mechanisms by which bioethical issues have been addressed in the USA. In view of the importance of American thought in the development of bioethics, more people working in other societies may find this useful than its parochial character may suggest. Readers who are not American citizens will, however, find it hard to see its relevance to their very different social institutions. An exception to this general statement is a remarkable background paper on trust and honesty in science by Steven Shapin. This is a valuable contribution to the growing argument that virtue and shared moral values are an essential ingredient in any functioning social enterprise; an argument which has been advanced by moral philosophers such as Macintyre and Midgley. For most bioethicists however, this is a book to refer to as background to understanding American institutions and political processes rather than to study as a contribution to developing their own.

PETER D TOON GP, Hackney, London

\section{Making Sense of Advance Directives (2nd ed)}

Nancy King, Washington DC, Georgetown University Press, 1996, 286 pages, $£ 15.90 /$ US $\$ 19.95$.

What did Richard Nixon and Jacky Onassis have most in common? Both died in mid-1994 in the same New York hospital but according to Nancy King, the thing which caught public attention about both deaths was the hospital's compliance with their "living wills", which refused treatment. These so fascinated the public that the hospital switchboard was jammed for days with enquiries about "choice in dying". Beyond the American health system, however, the notion of people documenting in advance how medical decisions should be made at the end of their lives barely impinges on public consciousness. For the world at large, the level of fear of over-treatment is swamped by greater anxiety about getting too little - or inequitable access to - health care. Nor have comparable public figures, such as the Queen or Mrs Thatcher, displayed the same assiduity as the former US president in giving a lead in such advance planning. Could it be that Americans are simply less fearful of contemplating death ... less thanatophobic than the rest of us?

On the contrary, one of the doubtlessly unintended themes of Nancy King's book is the contrast between the lukewarm public commitment to advance directives and the strong theoretical support for them from ethicists and law-makers. The book, which updates the 1991 version of the same title, seeks to convince clinicians and patients that they should give more serious attention to living wills. For, despite the publicity boost of the Nixon/Onassis demises, a dozen high-profile legal cases from Quinlan in 1976 to Cruzan in 1994, a plethora of books and articles (King lists over 200 reference titles), 89 federal acts on this issue and legislation requiring health facilities to promote advance directives in order to receive Medicare and Medicaid dollars, less than twenty per cent of Americans actually have one. This reluctance to think ahead about future mental incapacity and death spurs the author to suggest that "we could perhaps force a flowering of foresight" by legislating 
for every person without an advance directive to have mandatory medical treatment. Decide now or pay later. The intention behind this suggestion to make treatment obligatory and "force consensus by legislation" is primarily to spur to action those who have strong views but fail to document them. It is indicative of the book's underlying premise that unwanted medical treatment is likely to be the penalty for those whose choice is not to choose at all.

In this respect, perhaps, Making Sense of Advance Directives occasionally makes less than good sense. It presents a vision of advance directives as the way forward despite the fact that they are under-used, currently less popular in America than health care proxies and replete with problems which the author conscientiously documents. The current edition updates but also repeats the same points as the original 1991 version, the concluding chapter of which optimistically forecast an important future for advance directives, which "ultimately demonstrate the true nature of autonomy". The final chapter of the current edition begins in identical vein, reiterating the same emphasis on their popularity and significance. However, the reader may feel this is unsupported by any new evidence.

Intended for clinicians and patients, the book provides considerable detail and discussion about the use and limitations of living wills in the United States. There is something for everyone interested in the American endof-life debate, from a brief history of the concept of "informed consent" to model forms for the drafting of advance directives and conferring power of attorney. Much of the commentary and advice makes sound good sense. Patients are told they have "obligations to make their advance directives good guidance for others" or risk not getting what they want. Doctors are informed that advance directives "are not marching orders but documents of engagement". The significance of this military metaphor, however, resonates throughout as a sense of confrontation rather than cooperation permeates the text. The author herself is a proponent of advance directives, portraying them as an imperfect but potentially vital bulwark against doctors' determination to treat despite the odds. Her approach, while not continuously or virulently anti-medical, stresses that patients need to have advance decisions documented, witnessed and notarised if they wish to avoid doctors deciding for them. Formality and legality are of the essence, displacing notions of trust. While regrettable, this may well be a faithful reflection of American delivery of health care.

The underlying message is that doctors are unreliable in assessing patients' interests or making substituted judgments. Judges are often no better. True enough in general perhaps, although the author occasionally exaggerates the facts. "The earliest medical applications of substituted judgment" she explains "explicitly pitted medical against psychosocial views of the patient's best interests, giving court approval for subjecting mentally retarded patients to the medical demands of major surgery to donate kidneys to siblings of normal intellect". Visions are thereby conjured of cohorts of the mentally incapacitated going under the knife to satisfy "medical demands". The one case cited in which this actually occurred, however, has been a focus of debate for almost thirty years, precisely because of its exceptional and controversial nature. In the absence of other evidence, it should not be taken as indicative of a trend.

Additions to the earlier edition consist of references to the Cruzan case and the Patient Self Determination Act and a brief discussion of futility. The endnotes accompanying the text are also extensively and usefully expanded. As before, American case law since Quinlan is discussed and a state by state catalogue of relevant statute appended. No reference, however, is made to developments in other jurisdictions, although these have been closely imitative of US case law and reinforce some arguments the author supports. Disappointingly superficial is the handling of the complex debates about the continuity of personal identity and the financial and potentially pejorative implications of governments which promote treatment refusal. Both are raised in a perfunctory way although some additional references are cited for readers wishing to go further. Like its predecessor, the book is essentially practical and informative rather than philosophical or speculative.

The author's style is clear and accessible but occasionally irritating, varying from the portentous to the frivolous; from discussion of Aristotle, honour and nobility to the "rich Johnny-come-lately bumping others off the transplant list". Written for an American audience, the approach and compressed phraseology may seem alien to other readers. People become "decisionally incapacitated" and death is "a socially disfavoure choice". There is some repetition and: overlap between many of the chapter which, while useful for the reade $\bar{\sigma}$ wishing to dip into the book, can give the impression of over-emphasis or the usual, well-established arguments which recur throughout.

Consistency in medical decision making is clearly desirable but attimes the author seems to over-value uniformity and standardisation in $\vec{a}$ way incompatible with the vagaries messiness and unavoidable uncertain ties of real life. The quest for a stantD dard set of rules applicable to any casê without an advance statement convey a paralysing sense that no valid deci sion can ethically be made withoutr awareness of the individual's formen' wishes. Abuses, mistakes and dis옥 agreements do occur when the patient's views are unknown (and no all are avoidable by a living will). Buť treatment decisions are made, using as a criterion what seems humane ando reasonable in the particular circugnstances, without defying societarog professional standards. While encourro aging respect for the views of theses who are articulate about the kind of death they want, it must also be pos? sible to respect others who cannob bear to think about it or who mas simply be willing to trust health pro윽 fessionals to get it right. The book isclearly intended for those with af interest in exploring methods of extending choice within a sometimes్ unsupportive environment.

ANN SOMMERVILLE $B M A$, Dept of Medical Ethic\&

The Rules of Insanity: Moral Responsibility and the Mentally Ill Offender

Carl Elliott, Albany, State University of New York Press, 1996, $x$ and 143 pages, $\$ 17.95$ sc, $\$ 54.95$ hc.

The aim of this book is "to give some" answers to questions about the condizo tions under which mentally disē ordered people should be held morall responsible for their actions". Th $\frac{\Phi}{\$}$ answers turn out to be complex. Indeed, as Carl Elliott stresses, the title of his book is in part ironic because " $[\mathrm{m}]$ orally speaking, there are 